\title{
Physical capacity in community-dwelling elderly with and without acute low back pain. BACE Study
}

\section{Capacidade física em idosos comunitários com e sem dor lombar aguda. Estudo BACE}

Nayza Maciel de Britto Rosa', Daniele Sirineu Pereira², Bárbara Zille de Queiroz'1, Renata Antunes Lopes', Natalia Reynaldo Sampaio', Taisa Moreira Zenha', Leani Souza Máximo Pereira'

\begin{abstract}
The purpose of this study was to compare physical capacity in elderly with and without acute low back pain (LBP). The Back Complaints in the Elders (BACE) consortium is a prospective study conducted in Brazil, Australia, and Netherlands. This subsample consists of elderly BACE Brazil study volunteers. This is an observational, cross-sectional, and comparative study with older adults aged $\geq 65$ years who had a new episode (an agudization of symptoms) of LBP. Physical capacity was assessed using the Timed Up and Go test, Sit to Stand test, and normal Walking Speed test. Continuous variables were compared using a nonparametric Mann Whitney $U$ test. A chi squared test was used for categorical wariables. Significance level of $\alpha=5 \%$. The study included 104 elderly with mean age of $72.3 \pm 4.2$ years, classified into two groups: 52 elderly with LBP (GI) and 52 elderly without LBP (GII). The GI group showed worse performance in the Timed Up and Go $(p=0.000)$, Sit to Stand $(p=0.000)$ and normal Walking Speed $(p=0.002)$ tests than the GII group. Finally, the results of this study show the negative impact of LBP exacerbation on physical capacity in the elderly. Thus, it is important that health professionals involved in elderly care are attentive in the assessment and interpretation of clinical conditions regarding LBP to prevent negative impacts on physical function.
\end{abstract}

Keywords

Low Back Pain; Elderly; Physical Capacity; Functionality.

\section{Resumo}

O objetivo deste estudo foi comparar a capacidade física em idosos com e sem dor lombar (DL) aguda. O consórcio Back Complaints in the Elders (BACE) é um estudo prospectivo conduzido no Brasil, Austrália e Holanda. Esta subamostra consiste de idosos voluntários do estudo BACE Brasil. Este é um estudo observacional, transversal e comparativo com idosos de idade $\geq 65$ anos que apresentaram um novo episódio (uma agudização dos sintomas) de DL. A capacidade física foi avaliada usando o Timed Up and Go teste, o teste de sentar e levantar da cadeira e velocidade da marcha. As variáveis contínuas foram comparadas usando o teste não paramétrico Mann Whitney U. O teste do qui-quadrado foi usado para variáveis categóricas. O nível de significância considerado foi $\alpha=5 \%$. O estudo incluiu 104 idosos com idade média de 72,3 $\pm 4,2$ anos, classificados em dois grupos: 52 idosos com DL (GI) e 52 idosos sem DL (GII). O grupo GI apresentou pior desempenho nos testes Timed Up and Go $(p=0,000)$, sentar e levantar da cadeira ( $p$ $=0,000)$ e velocidade da marcha $(p=0,002)$, do que o grupo GII. Os resultados deste estudo mostram o impacto negativo da exacerbação da DL na capacidade física em idosos. Assim, é importante que os profissionais de saúde envolvidos no cuidado ao idoso estejam atentos à avaliação e interpretação das condições clínicas que envolvam a DL para prevenir impactos negativos na função física.

\section{Palavras-chave}

Dor lombar; Idoso; Capacidade física; Funcionalidade.

\section{Introduction}

Pain is one of the most common reasons for older people to seek medical attention. ${ }^{1}$ Low back pain (LBP) is common in the elderly, with a prevalence of $12-42 \%$ in individuals over the age of 65 years, and

1 Universidade Federal de Minas Gerais, Department of Physical Therapy, Postgraduation Program in Rehabilitation Sciences, Belo Horizonte, Minas Gerais, Brazil. 2 Universidade Federal de Alfenas, Department of Physical Therapy, Alfenas, Minas Gerais, Brazil. is a musculoskeletal disorder most commonly found in those over the age of 75 years. A systematic review showed that the prevalence of LBP of low to moderate intensity decreases with advancing age, after a peak occurs in the sixth decade. However, the most intense LBP continues to increase with aging ${ }^{2}$.

LBP is a complaint of great importance among the elderly due to its significant impact on function ${ }^{3}$. Impaired capacity physical has been identified as a 
strong predictor of future disability, decreased mobility, institutionalization, and mortality in older people ${ }^{1}$. However, the effect of acute LBP on the physical capacity of older patients is not well known. To our knowledge, there is not other study that examined brazilian elderly with and without acute LBP evaluated through a battery of functional tests. The research is focused mainly on the economically active population, between 18-65 years of age. Moreover, even when different age categories are compared, older people are underrepresented and some research studies explicitly exclude elderly patients aged $\geq 60$ or 65 years ${ }^{4}$. However, the results of studies in a younger population cannot necessarily be generalized to the elderly. The prevalence of disc degeneration, osteoarthritis, osteoporosis, and spinal stenosis increases with age. Moreover, peculiar aspects of the aging process such as sarcopenia and frailty and different outcomes in terms of prognosis such as falls, institutionalization, disability, and hospitalization must be considered. Another difference may occur in the treatment of LBP in the elderly, since the elderly have more comorbidities and may have more adverse reactions to medication ${ }^{4}$.

The International Classification of Functioning, Disability and Health (ICF) model, proposed by the World Health Organization (WHO), provides a structure for understanding the classification of functioning and disability associated with health conditions ${ }^{5}$. The ICF uses capacity physical constructs to evaluate subject' functional status. The capacity construct is used to describe an individual's ability to execute a task or an action in a standardized environment and it is useful to indicate the highest probable level of functioning that a person can reach in the domain that is being evaluated ${ }^{5}$. Functional tests are standardized functional instruments that are used to evaluate the patient's capacities to execute physical activities. Functional tests measure the highest probable level of functioning that a person may reach in an activity domain in a standardized environment ${ }^{6}$. To evaluate the physical capacity of LBP patients, some specific tests for these aspects of functioning can be used, such as the Sit to Stand test, the Walk test, and the Timed Up and Go test, among others?

The ICF postulates that functionality and disability can be described in three health domains: body functions and structure, activity, and participation. The body functions and structure domain is characterized by physiological and/or psychological functions of body systems and their anatomic parts ${ }^{5}$. In the case of LBP in the elderly, it is common to see some changes in this domain, such as pain, weakness, muscle imbalance, muscle spasm, decreased muscle flexibility, decreased joint mobility, and postural changes, among others ${ }^{8}$ The activity related domain describes the ability of an individual to perform a task or action of their daily routine. Elderly with LBP often have difficulties in walking, sitting and rising from a chair, climbing up and down the stairs, and picking up objects which are lying on the ground ${ }^{9,10}$ This health condition also affects the individual's participation in sociocultural activities. In such cases, it is common to see a restriction in the social life of elderly with LBP.

The complications caused by low back pain may lead the elderly to a physical inactivity cycle, known as the "vicious aging cycle," which can further worsen other physical, psychological and social conditions. Physical inactivity causes physical deconditioning that generates a musculoskeletal frailty, leading to independence loss, making the individual feel less motivated and lower self-esteem, which can cause psychological disorders such as anxiety and depression that will generate more physical inactivity ${ }^{11}$.

A better understanding of the physical capacity of the elderly with LBP may contribute to a better comprehension of the health-disease process experienced 
by LBP patients, allowing health professionals to formulate therapeutic problems and objectives according to the specific functional profile of each individual ${ }^{3}$.

There is a clear need for a comprehensive battery of simple and objectively measurable functional tests for elderly patients with LBP. Such a test battery must include tasks that are fundamental to day-to-day activities and that are compromised by LBP, for example, lifting, walking, and sitting. The purpose of this study was to compare the performance of elderly with (GI) and without LBP (GII) on a battery of physical performance tasks.

\section{Methods}

\section{Study Design and Participants}

The Back Complaints in the Elders (BACE) consortium is a prospective study and its detailed protocol was published elsewhere ${ }^{4}$. This subsample consists of elderly BACE Brazil (BACE B) study volunteers who participated in the GI. This is an observational cross-sectional and comparative study with older adults aged 65 years and over who had a new episode of low back pain. LBP was defined as pain in the area between the shoulder blades and the $\mathrm{S} 1$ vertebrae ${ }^{12}$. The episode was defined as new if the person did not seek medical attention for care due to LBP during the six months before data collection. Moreover, for the BACE B study, participants would also have to present themselves with an agudization of symptoms, which was defined as an episode of acute pain within six weeks of the recruitment period. A person would be invited to participate in the study by our research team only if they met these criteria.

For the BACE B study, older adults were recruited as convenient by our research team. First, older adults were referred by physicians or allied health care professionals from either public or private healthcare in Brazil to contact the BACE B research team in case of LBP complaints. Then, they were screened by the research team to see if they could be included in the study, according to the previously stated criteria. All elderly subjects were clinically stable and fully capable of walking by themselves with or without walking aids.

The GII (control group) included community-dwelling elderly, aged $\geq 65$ years, without LBP. All elderly subjects were clinically stable and fully capable of walking by themselves with or without walking aids. The sample of elderly without LBP was recruited in groups of seniors or who were on the waiting list at the Escola de Educação Física, Fisioterapia e Terapia Ocupacional (EEFFTO) of UFMG after verification of inclusion and exclusion criteria.

Participants were excluded if they presented any severe visual, motor, or hearing loss; used a wheelchair or were bedridden; or had cognitive dysfunction ${ }^{13}$ that would prevent them from being assessed during the study period. The BACE B study was approved by the Ethics Committee of the Universidade Federal de Minas Gerais (UFMG), Brazil (ETIC 0100.0.203.000-11). All participants signed a Term of Free and Informed Consent.

The effect size index values (d) for each variable were calculated using as a basis the average mean and standard deviation of the pilot study of 10 healthy elderly people. From these values, the sample sizes required to have power values equal to 0.80 using the 0.05 significance level were estimated. Thus, it was determined that there needed to be 52 subjects in each group.

\section{Measuring Instruments}

To characterize the sample, participants were interviewed by trained researchers who used an elaborate sociodemographic and clinical questionnaire. The ques- 
tionnaire was standardized by the group of researchers who comprise the BACE study ${ }^{4}$. The short version of the Geriatric Depression Scale (GDS-15) was used to quantify depression symptoms ${ }^{14}$, and the short version of the International Physical Activity Questionnaire (IPAQ-short) was used to investigate the physical activity levels of participants, with the analysis of all domains of the questionnaire ${ }^{15}$.

\section{- Physical capacity}

Physical capacity was assessed by a battery of functional tests that included the Timed Up and Go (TUG) test, normal Walking Speed (WS) test, and Five Times Sit to Stand Test (5xSST). These tests were used because they have demonstrated high reliability, they involve common daily tasks, are commonly used to assess function in elderly people and the tests are compromised by LBP. Moreover, they are suitable tests to assess the physical capacity of elderly with $\mathrm{LBP}^{7}$.

The TUG measures, in seconds, the time taken to stand up from a standard chair, walk a distance of 3 meters, turn, walk back to the chair, and sit down. The TUG score demonstrates high inter-rater and intra-rater reliability (intraclass correlation coefficients (ICCs) 0.99 and 0.99 respectively) ${ }^{16}$. The TUG was initially developed to measure functional mobility and in fact, has been recommended as a simple falls risk screening tool. It includes transfer tasks (standing up and sitting down), walking, and turning and incorporates neuromuscular components such as balance.

Normal WS is a valid, reliable, sensitive, and specific measurement, and is a good marker for mobility, loss of independence, decreased life quality, and increased mortality ${ }^{17}$. Normal WS was calculated using the time (in seconds), a subject required to walk 4.6 meters at a normal pace. The elderly walked a total distance of 8.6 meters, but the initial and final 2 meters were disregarded due to walking acceleration and deceleration.

The 5xSST measures the time a person takes to stand up from a chair and sit back in the chair five times as fast as possible. Getting up from a chair is a common task that elderly with LBP perform slowly. The test involves stress on the trunk ${ }^{7}$. It has been used as an assessment tool for disability and risk for falls and as an indicator of lower limb strength in the elderly, with scores presenting excellent test-retest reliability $(\mathrm{ICC}=0.89)^{18}$.

\section{- Low back pain intensity}

Low back pain intensity was evaluated according to a numerical scale of pain classification characterized by a discontinuous scale of whole numbers ranging from 0 (no pain) to 10 (the worst pain ever). LBP intensity was evaluated twice: at the moment of filling in the questionnaire and the average intensity of back pain in the last week. This scale is an instrument that is used internationally in elderly people with high reliability and reproducibility ${ }^{19}$.

\section{Statistical analysis}

Descriptive statistics were used for the sample characterization. Kolmogorov-Smirnov test was used to verify the distribution of data. The comparison analysis between groups for continuous variables was performed by a nonparametric Mann Whitney U test for data with a non-normal distribution. A chi squared test was used to compare categorical variables. All of the analyses involved a significance level of $\alpha=5 \%$ and were performed with the Statistical Package for the Social Sciences version 17.0, Windows.

The relationship between pain and physical capacity in older people may also 
be confounded by other factors such as depression, comorbidities, level of physical activity, and cognition, which influence both pain and physical performance ${ }^{1}$. In order to reduce the impact of cognition on physical capacity, elderly with a possibility of cognitive impairment ${ }^{13}$, were excluded.

\section{Results}

Study participants were 104 elderly, with average age 72.3 (Standard Deviation $(\mathrm{SD})=4.0$ ) years with a minimum age of 65 and maximum of 88 years. The average schooling group was $8.1(\mathrm{SD}=3.9)$ years. Most of the sample consisted of divorced, separated, or widowed persons. A description of the clinical and demographic variables is included in Table 1.

TABLE 1 - Comparison between groups Gl and Gll: descriptive variables.

\begin{tabular}{lccccc}
\hline & \multicolumn{2}{c}{$\begin{array}{c}\text { Group Low Back Pain (GI) } \\
\mathrm{n=52}\end{array}$} & \multicolumn{2}{c}{$\begin{array}{c}\text { Control Group (GII) } \\
\mathrm{n=52}\end{array}$} & p value \\
\hline & Mean (SD) & Median & Mean (SD) & Median & \\
\hline Age (years) & $70.6(3.9)$ & 70.5 & $74.1(4.2)$ & 73.5 & $0.458^{\#}$ \\
\hline $\begin{array}{l}\text { Depressive symptoms } \\
\text { (GDS score/15) }\end{array}$ & $4.9(2.6)$ & 4.0 & $2.6(1.8)$ & 2.5 & $0.000^{* \#}$ \\
\hline Comorbidities (n) & $2.4(1.2)$ & 2.0 & $1.7(1.0)$ & 1.0 & $0.005^{* \#}$ \\
\hline $\begin{array}{l}\text { Physical activity level } \\
\text { (IPAQ/MET. min/week) }\end{array}$ & $1879.3(1831.4)$ & 880.0 & $2270.9(1841.9)$ & 1680.0 & $0.452^{\#}$ \\
\hline Gender \% & & & & $0.747 \dagger$ \\
\hline Female & $92.3 \%$ & & & \\
\hline Male & $7.7 \%$ & & & \\
\hline
\end{tabular}

* Significant difference between the groups $\mathrm{p}<0.05$; \& t test; \# Mann-Whitney test; $†$ chi squared test. GDS=Geriatric Depression Scale; IPAQ=Physical Activity Questionnaire; MET=metabolic equivalent task; SD=standard deviation.

There was no significant difference between GI and GII regarding age, gender, and level of physical activity, demonstrating that the groups were homogeneous with each other. There were significant differences in the number of comorbidities and depressive symptoms (Table 1). The elderly group with LBP showed worst physical capacity, with longer execution times of TUG test, $5 x$ SST and WS when compared to GII (Table 2). In the descriptive analysis of the variables for GI, the mean intensity in numerical scale of pain was 4.1 points "at this time" and 6.2 points "in last week."

TABLE 2 - Comparison between groups Gl and Gll: physical capacity.

\begin{tabular}{|c|c|c|c|c|c|}
\hline & \multicolumn{2}{|c|}{$\begin{array}{l}\text { Group Low Back Pain (Gl) } \\
\qquad n=52\end{array}$} & \multicolumn{2}{|c|}{$\begin{array}{c}\text { Control Group } \\
\begin{array}{c}\text { (GII) } \\
n=52\end{array}\end{array}$} & \multirow[t]{2}{*}{$p$ value } \\
\hline & Mean (SD) & Median & Mean (SD) & Median & \\
\hline TUG (seconds) & $12.0(2.3)$ & 12.13 & $8.9(1.2)$ & 8.6 & $0.000^{* \#}$ \\
\hline WS (seconds) & $5.2(1.3)$ & 4.8 & $4.2(0.6)$ & 4.1 & $0.002^{* \#}$ \\
\hline 5XSST (seconds) & $17.7(4.0)$ & 16.1 & $13.1(1.9)$ & 12.8 & $0.000^{* \#}$ \\
\hline
\end{tabular}

* Significant difference between the groups p <0.05; \# Mann-Whitney test. TUG=Timed Up and Go Test; WS=normal Walking Speed Test; 5xSST=5-chair Sit-to-stand test; SD=standard deviation.

\section{Discussion}

This study confirmed that the elderly group with LBP exacerbation had the worst results in the functional performance tests. There is evidence that the intensity 
of the pain diminishes functional capacity ${ }^{1}$. It has been shown that middle-aged adults with LBP perform significantly worse than healthy controls on some physical performance tests, for example the TUG and $5 \times S S T$ tests ${ }^{7,20}$.

Acute LBP is perceived as an interference, which can lead to an increase in the threshold of nociceptive afferents in the low back, further causing interference on the spinal motor via the motor cortex. Additionally, pain can cause an increase in presynaptic muscle afferents inhibition and affect proprioceptive receptors modulation, causing long latency due to a decrease in muscle spindle feedback ${ }^{21}$. Thus, motor responses are slower and can reduce the physical capacity in the elderly.

Acute LBP can also lead to alterations in the normal upright position as well as inhibition of muscle activation for the protection of injured tissues ${ }^{22}$. These compensatory changes in posture and muscle activation patterns may occur as a strategy for limiting the movements of the spine and avoiding movements that trigger pain, leading to a change in balance and postural control. The protection mechanism against pain can also lead to a decline of mobility and functionality. The TUG, 5xSST and WS are simple tests that reproduce functional daily activities of elderly and require lumbar spine participation. The decreased performances in these tests suggest a reduction in mobility and a loss of quality of life and independence, among other factors. Due to the pain in this region, the physical capacity of the person would be compromised and this could explain the decreased performance of the group with LBP. Furthermore, a recent LBP episode can indirectly generate kinesiophobia, activity restriction, and consequent reduction of exercise capacity ${ }^{23}$.

Regarding chronic LBP, Rudy et al. showed that elderly with LBP for $\geq 3$ months showed worse physical capacity than elderly without pain ${ }^{24}$. Neuromuscular effects of chronic pain may lead to muscle weakness or a slower neuromuscular response $e^{25}$. These changes may lead to muscle control loss and result in a worse performance in physical capacity tests.

Studies showed that LBP was associated with physical disability. In the Edmond and Felson study ${ }^{26}$, community-dwelling elders with LBP reported difficulty in remaining in the standing position for a long time, pulling or pushing an object, and walking a distance of approximately 800 meters. Leveille reports that elderly women with LBP had greater difficulty in performing basic and instrumental activities of daily living, than asymptomatic women ${ }^{25}$.

In Weiner et al. study ${ }^{9}$, LBP was associated with longer time sitting and rising from a chair, slower gait speed, reduced knee extension and hip flexor's strength. There was a linear relationship between severity of pain and shortage of physical capacity. In another study by the same author with 323 seniors with chronic LBP due to column osteoarthritis, pain intensity was significantly associated with physical test results in terms of gait speed, functional range, getting up from the chair, trunk rotation, and lifting static and dynamic weight ${ }^{10}$. In the Di Lorio et al. study, the activities that were most commonly associated with CLBP due to disability were bathing, washing clothes, doing heavy household chores, cutting nails, shopping, and carrying bags ${ }^{27}$.

The functional tests (5xSST, normal WS, TUG) chosen for the study have been shown to be suitable for the evaluation of the physical capacity of elderly with LBP. Moreover, they are quick and cost-effective measures that can easily be performed in the clinical setting. The tests not only serve the purpose of documenting outcomes, but also to provide parameters to be directly trained or rehabilitated in order to improve function. 
The purpose of the rehabilitation of elderly with LBP is to promote not only an improvement in physical parameters, such as muscle strength, flexibility and mobility, but also an improvement in functional status, allowing the return to usual activities ${ }^{3}$. This reinforces the importance to consider the specific functional profile of each elderly in assessment and intervention procedures.

There was no difference between the groups for sociodemographic characteristics and physical activity level (Table 1). These data reinforce the fact that the differences between elders with and without acute LBP in the study's main variable may even have occurred for physical capacity issues.

Regarding co-variables, there was a significant difference between GI and GII for depressive symptoms and comorbidities. The relationship between depression and disability in elderly with LBP can be explained trough the fact that pain can make these individuals feel helpless and disabled, and have less motivation to do their best performance in the activities. On the other hand, symptoms common to depression, such as negative thoughts and self-perceived fatigue will interfere with how elderly with LBP deal with the pain and contribute to the presence of disability $^{28}$. Comorbidity is common in elderly patients with LBP and is associated with poorer prognosis ${ }^{4}$. According to Rudy et al. ${ }^{24}$, elderly with LBP had more comorbidities than elderly without LBP. In addition, comorbidities influence disability in the elderly and may have larger impact of health related quality of life in patients with $\mathrm{LBP}^{29}$. However, the fact that elderly with LBP have more depressive symptoms and comorbidities didn't cause them to reduce their physical activity level compared to the control group, so that there was no significant difference in the group for this variable.

This study has some limitations. The BACE survey used self-reporting to identify LBP instead medical diagnostic. However, self-reported measures are commonly used in clinical practice, research, and large epidemiologic studies because they are simple, reliable, and low-cost, making them suitable for quality assurance in research ${ }^{30}$.

In conclusion, the results of this study show the negative impact of LBP exacerbation on physical capacity. Elderly patients with LBP had significantly lower scores in the battery of physical performance tasks than elderly patients without LBP. Thus, it is important that health professionals involved in elderly care are attentive in the assessment and interpretation of clinical conditions regarding LBP to prevent negative impacts on physical function. Studies should be encouraged to trace the clinical and functional course of elderly with LBP in order to present specific assessments and treatments for elderly with LBP.

\section{Acknowledgements}

This study was supported by FAPEMIG, CNPq, CAPES and Pró-Reitoria de Pesquisa da UFMG. The authors report no conflicts of interest in this work.

\section{References}

1. Pereira LS, Sherrington C, Ferreira ML, Tiedemann A, Ferreira PH, Blyth FM, Close JC, et al. Self-reported chronic pain is associated with physical performance in older people leaving aged care rehabilitation. Clin Interv Aging. 2014;9:259-65.

2. Dionne CE, Dunn KM, Croft PR. Does back pain prevalence really decrease with increasing age? A sistematic review. Age and Agein. 2006;35:229-34.

3. Ocarino JM, Gonçalves GGP, Vaz DV, Cabral AAV, Porto JV, Silva MT. Correlation between a functional performance questionnaire and physical capability tests among patients with low back pain. Rev Bras Fisioter. 2009;13:343-49. 
4. Scheele J, Luijsterburg PA, Ferreira ML, Maher CG, Pereira L, Peul WC, et al. Back Complaints in the Elders (BACE); design of cohort studies in primary care: an international consortium. BMC Musculoskelet Disord. 2011;12:193.

5. World Health Organization. International classification of functioning, disability and health: ICF. WHO: Geneva; 2001.

6. van Abbema R, Lakke SE, Reneman MF, van der Schans CP, van Haastert CJ, Geertzen JH, et al. Factors associated with functional capacity test results in patients with non-specific chronic low back pain: a systematic review. J Occup Rehabil. 2011;21:455-73.

7. Simmonds MJ, Olson SL, Jones S, Hussein T, Lee CE, Novy D, et al. Psychometric characteristics and clinical Usefulness of Physical Performance Tests in Patients with low back pain. Spine. 1998;23(22):2412-21.

8. Godges JJ, Varnum DR, Sanders KM. Impairment-based examination and disability management of an elderly woman with sacroiliac region pain. Phys Ther. 2002;82(8):812-21.

9. Weiner DK, Haggerty CL, Kritchevsky SB, Harris T, Simonsick EM, Nevitt M, et al. How does low back pain impact physical function in independent, well-functioning older adults? Evidence from the Health $\mathrm{ABC}$ Cohort and implications for the future. Pain Med. 2003;4:311-20.

10. Weiner DK, Rudy TE, Morrow L, Slaboda J, Lieber S. The relationship between pain, neuropsychological performance, and physical function in community-dwelling older adults with chronic low back pain. Pain Med. 2006;7:60-70.

11. Nóbrega ACL, Freitas EV, Oliveira MAB, Leitão M, Lazzoli JK. Posicionamento oficial da Sociedade Brasileira de Medicina do Esporte e da Sociedade Brasileira de Geriatria e Gerontologia: atividade física e saúde no idoso. Rev Bras Med Esporte.1999;5(6):207-11.

12. Dionne CE, Dunn KM, Croft PR, Nachemson AL, Buchbinder R, Walker BF, et al. A consensus approach toward the standardization of back pain definitions for use in prevalence studies. Spine 2008;33:95-103.

13. Bertolucci PH, Brucki SM, Campacci SR, Juliano Y, et al. The mini-mental state examination in a general population: impact of educational status. Arq Neuropsiquiatr. 1994;52:1-7.

14. Almeida OP, Almeida SA. Reliability of the Brasilian version of the abbreviated form of geriatric depression scale (GDS) short form. Arq Neuropsiquiatr. 1999;57:421-26.

15. Matsudo S, Araujo T, Matsudo V, Andrade D, Andrade E, Oliveira LC, et al. International physical activity questionnaire (IPAQ): study of validity and reliability in Brazil. Rev Bras Ativ Fis Saúde. 2001;6:05-18.

16. Bohannon RW. Reference values for the Timed UP and Go Test: A descriptive MetaAnalysis. J Geriatr Phys Ther. 2006;29:64-68.

17. Studenski S, Perera S, Patel K, Rosano C, Faulkner K, Inzitari M, et al. Gait Speed and Survival in Older Adults. JAMA. 2011;305:50-58.

18. Tiedemann A, Shimada H, Sherrington C, Murray S, Lord S. The comparative ability of eight functional mobility tests for predicting falls in community-dwelling older people. Age Ageing. 2008;37:430-35.

19. Williamson A, Hoggart B. Pain: a review of three commonly used pain rating scales. J Clin Nurs. 2005;14:798-804.

20. Teixeira da Cunha-Filho I, Lima FC, Guimaraes FR, Leite HR. Use of physical performance tests in a group of Brazilian Portuguese-speaking individuals with low back pain. Physiother Theory Pract. 2010;26:49-55.

21. Ruhe A, Fejer R, Walker B. Is there a relationship between pain intensity and postural sway in patients with non-specific low back pain? BMC Musculoskelet Disord. 2011;12:162.

22. Danneels LA, Vanderstraeten GG, Cambier DC, Witvrouw EE, De Cuyper HJ. CT imaging of trunk muscles in chronic low back pain patients and healthy control subjects. Eur Spine J. 2000;9:266-72.

23. Langevin HM, Sherman KJ. Pathophysiological model for chronic low back pain integrating connective tissues and nervous system mechanisms. Med Hypotheses. 2007;68:74-80.

24. Rudy TE, Weiner DK, Lieber SJ, Slaboda J, Boston JR. The impact of chronic low back pain on older adults: A comparative study of patients and controls. Pain. 2007;131:293-301.

25. Leveille SG, Jones RN, Kiely DK. Chronic musculoskeletal pain and the occurrence of falls in an older population. JAMA. 2009;302:2214-21. 
26. Edmond SL, Felson DT. Function and back symptoms in older adults. J Am Geriatr Soc. 2003;51:1702-09.

27. Di Iorio A, Abate M, Guralnik JM, Bandinelli S, Cecchi F, Cherubini A, et al. From chronic low back pain to disability, a multifactorial mediated pathway: the InCHIANTI study. Spine. 2007;32:809-15.

28. Marcic M, Mihalj M, Ivica N, Pintaric I, Titlic M. How severe is depression in low back pain patients. Acta Clin Croat. 2014;53:267-71.

29. Brox JI, Lange JE, Steen H. Comorbidity influenced health-related quality of life of 390 patients with idiopathic scoliosis at long-term follow-up. Eur J Phys Rehabil Med. 2014;50:73-81.

30. Costa LO, Maher CG, Latimer J. Self-report outcome measures for low back pain: searching for international cross-cultural adaptations. Spine. 2007;32:1028-37.

CORRESPONDING

\section{AUTHOR}

NAYZA MACIEL DE BRITTO ROSA

nayzabritto@yahoo.com.br
Department of Physical Therapy,

Federal University of Minas Gerais,

Avenida Antônio Carlos, 6627, CEP

31270-901, Belo Horizonte, Minas Gerais

Telephone: (0XX31) 3499-4783

Fax: (0XX31) 3499-4781
RECEIVED 05/11/2015

REVISED 25/05/2016

APPROVED 22/07/2016 